\title{
Pedagogical Implications for Using a Wiki in Peer-to-Peer Learning Environments
}

\author{
Lisa Russell
}

\begin{abstract}
The pedagogical potentials and challenges experienced when trying to incorporate the use of a wiki social media site with undergraduate childhood study students are reported. The wiki was introduced to inspire students to engage in student peer-learning, develop their writing skills, and facilitate a PhD student's developmental teaching beyond the dissertation phase from PhD student to scholar. Although these aims were achieved to a degree, they were reached in unexpected ways. A "community of practice" (Lave \& Wenger, 1991) was evident within the actual seminar session space rather than within an online community capacity.
\end{abstract}

\section{Background}

There is an emergent demand to design learning experiences in Higher Education (HE) that develop collaborative and mediated social practices (Page \& Reynolds, 2015). There is recognition that students are entering HE with a different skill set and are engaging with lectures and seminars in changed ways (Cole, 2009). Alongside this shift there is a movement towards more student-centred learning (Jonassen, Peck, \& Wilson, 1999). HE educators are increasingly looking towards more participatory, reflective teaching practices, which has generated a growing interest in the use of web-based technology to create more flexible, interactive learning environments. Working collaboratively has shown to improve learners' ability to understand and retain information (Johnson \& Johnson, 1986). Participatory learning among peers has evidenced improved student engagement (Cole, 2009), enhanced writing capabilities (Page \& Reynolds, 2015), and developed pedagogic learning amongst new lecturers within a university teaching context (Warhurst, 2006). It is against this backdrop that the use of the wiki as an innovative teaching tool has emerged. This paper examines the pedagogic learning of 25 Undergraduate Childhood Study students and one Sociology of Education PhD student's new co-teaching lecturing experiences related to constructing and maintaining the related wiki site. The lens of situated learning theory (Lave \& Wenger, 1991) is used to gain insight into the ways in which the degree of full or periphery participation within the wiki online and physical seminar "community of practice" space enhanced learner understanding and writing capabilities if managed in a mediated and (re)negotiated way. 


\section{Wiki Context}

A wiki is a

hypertextual system for storage and transmission of information. Every page on a wiki is created and editable through the web using a web browser. The vision of wikis is an evolution from plain hypertextual systems for learning and information retrieval. Wikis facilitate the connection between community and content. The success of Wikipedia is the most prominent example of the potential of the wiki concept. (Ravid, Kalman, \& Rafaeli, 2008, p. 1915)

Wikis are usually discussed from two perspectives, as a software tool used to achieve social learning goals and as a social practice through which mediated social contexts are created and collaborative learning is experienced by a collective (Page \& Reynolds, 2015). The use of wiki practices fosters a collaborative, egalitarian learning that facilitates group interaction and challenges traditional studentteacher modes of learning (Ruth \& Houghton, 2009). Pages are co-created by members to form a collective network structure ripe for communal editing, shared knowledge, and constructing understanding, so that data and writing are co-produced and continually renegotiated, amended, and developed. This differs from the traditional mode of a single person digital design or a one-way mode of communication cognizant with email (Mindel \& Verma, 2006) or from document-sharing services which act as a collective data storage space with independent document editing capabilities such as Dropbox or Google Drive (Page \& Reynolds, 2015). From a social practice perspective, a wiki is viewed as a social practice within and through which learning emerges from member interactions co-created within the social and learning context. The learning experience is negotiated via the group, rather than on an individual basis, making within-group and virtual team working possible. Wikis have been viewed as a revolutionary educator tool that enhance peer group learning and undergraduate writing capabilities, as well as helping new university lecturers develop their pedagogic practice and lecturer identity.

\section{Situated Learning in Communities of Practice}

Situated learning theory offers a radical critique to cognitivist theories of learning that accentuate the individualistic assumptions of learning as a discrete and decontextualized activity, founded on a positivist assessment of abstract knowledge. Rather, the relational aspects of learning and the social construction of knowledge is emphasized within a context of community of practice. Learning is thought as emerging through membership in a community and not as primarily abstract. The wiki can be viewed as a community of practice, as a virtual space whereby learning and identity are co-constructed for the undergraduates, the PhD student and indeed the lecturer, but also the physical space of the seminar gathering is important. Levels of participation can be analyzed and all degrees are accepted as valid with the peripheral participator moving towards full participation as time goes on. Situated learning theory positions the community of practice as the context in which an individual develops the practices (including values, norms, and relationships) and identities appropriate to that community (Handley, Sturdy, Fincham, \& Clark, 2006). This differs from theories of socialization (e.g., Vygotsky, 1978) which assume a natural reproduction of values, norms, and identities over time. Within situated learning theory, individuals bring their own personal history and norms to the group, which may or may 
not comply with one another in the community context. Such differences need to be (re)negotiated and reconciled if the individual is to achieve a feeling of belonging to the community. This means that there needs to be an understanding of the individual's and the groups situated learning within and beyond the community (Handley et al., 2006), but also an acceptance that the learners enter the community or wiki space with a set of personal characteristics and values that can be safely discussed and (re)negotiated within the seminar group pedagogical practices. Whilst peer-group learning has been analyzed within this theoretical context in relation to the use of wikis, the postgraduate learners' identity formation and pedagogic development beyond that of the doctorate have been given less consideration. The use of the wiki here is analyzed in terms of group and individual use, both within the physical space of the seminar room and beyond to include that of the virtual space.

\section{Using and Analyzing the Pedagogic Value of the Wiki}

The wiki was created and used with one seminar group across several sessions from October 2015 to April 2016. This one group was selected as a pilot in preparation for the use of the wiki the following academic year. The rationale behind this was twofold; firstly, to inspire students to engage in student peer-learning and start writing in an academic undergraduate format-a problem that has long since been identified as a challenge for this year's group on this particular module, and secondly to integrate and develop a PhD student's developmental teaching beyond the dissertation phase to help her make the transition from PhD student to scholar. My PhD student participated with online discussions and was

encouraged to add relevant material and assist with the general set-up and ongoing maintenance and monitoring of the wiki. She and I also did some co-teaching on the module.

For the purpose of the experimental teaching session, the wiki was stored, administered, and accessed through "unilearn" - the University's virtual learning environment that provides access to electronic documents, social media tools, and assignment submission tools to support students' studies. IT support was thus readily accessible and students could access all seminar work in one place.

At the start of the module and academic term, the first-year childhood study undergraduates were introduced to the notion of a wiki via a group discussion led by the lecturer and use of the YouTube link uploaded by Common Craft (2007), "Wikis in Plain English." Together, a home page was developed to include the YouTube link and a "Wiki do's and wiki don'ts" page that resulted from the seminar discussion between the students and the lecturer. The students were aware that this was a pilot and that the lecturer was also new to using wikis. The list comprised the following:

Wiki do's and don'ts page

\section{Wiki Do's}

HAVE A GO!

Post relevant information related to the module (these can include book chapters, journal articles, YouTube clips, images, or newspaper articles). 
Be respectful in your tone but do voice your opinion.

\section{Wiki Don'ts}

Avoid malicious comments and arguments.

Cite original sources for assignments.

An ideas page was established to encourage the undergraduates and the PhD student to add relevant images, website links, newspaper articles, books and journal references. During the initial stages, there were technical issues setting up the site and getting access for all students. Students needed reminding about how to access the wiki and what its purpose was. After the first month, it became apparent that both the undergraduates and postgraduate required clear direction from me in terms of what resources to input, types of activities to engage with, and set tasks to complete. Consequently, activities were set and executed in session to actively engage the students and develop a community of practice. With encouragement, students started to insert photographs of their seminar group work and some extra resources were entered. Both undergraduates and the $\mathrm{PhD}$ student seemed reluctant to voice their own opinions and write independently and confidently on the wiki, so I instigated group discussions around set topics and asked students to form group-written answers to relevant questions. Fostering a mutual community of practice took time and constant direction. Although some students used the wiki, most of this was done in seminar under lecturer direction, rather than taking on a life of its own. I had to do more than simply build it.

Findings are taken from two 20-minute focus group interviews with the seminar undergraduates and one 15-minute semi-structured interview with the PhD student (in February 2016) to explore their experiences of contributing to the wiki and their learning processes and outcomes. All interviews were transcribed and hand-coded. All data was triangulated alongside the document analysis of the actual wiki site content; frequency of use of wiki resources within assessments and my weekly wiki diary to analyze the use and content of the wiki, the student's contribution and level of participation with the wiki inside and outside of the seminar space (inside space is defined as the physical space of the seminar room and actual time of scheduled seminar, as opposed to outside space, which includes anything beyond this) and how use of it may be improved.

\section{From PhD Student to Scholar}

Part of the rationale for setting up the wiki was to aid my PhD student's academic career trajectory after (the near) completion of the $\mathrm{PhD}$. The doctor of philosophy $(\mathrm{PhD})$ degree is intended to prepare students to conduct original scholarly research for the thesis and beyond (Fleming-May \& Yuro, 2009). Postdoctoral training is vital to a successful career for education-based researchers to help them gain substantive knowledge and expand their research repertoire. Evidence suggests that PhD students experience difficulty navigating this transition and require further support (Downs \& Morrison, 2011). HE institutions and PhD supervisors can assist this transition for those who wish to make the shift via 
supporting students beyond the doctorate with their writing (for publication and grant awards) and teaching. It is within this ethos and the mutual support offered by the PhD student and the lecturer in terms of maintaining and actively contributing to the wiki that the postgraduate student (PG) was invited to take part and inject a new voice and fresh material to the wiki site. While use of the wiki helped the PhD student and added to her teaching repertoire, this participation alone was not sufficient to fully support her desired academic-based career trajectory.

LR: Is there anything that you've learnt through doing those seminars or doing some developmental work on the wiki?

PG: $\quad$ Yeah. One of the things that I've picked up is about how to engage less forthcoming students particularly the first-year students, I learnt how to kind of re-engage them with material at a later date and that's been particularly useful for me. It's been useful to see how a seminar is run in a university as opposed to a college.

LR: $\quad$ Did it help in terms of your confidence or thinking about what you might do next in your career?

PG: I think it's given me a bit more confidence, I wasn't entirely sure about how the teaching that I'm involved with at the moment would be different in a university setting and when I was an undergraduate student I was at a red brick university in a huge cohort so it was very different to how things are run here so, in terms of confidence, it's made me realise that there are differences but there are also quite a lot of similarities in terms of the actual teaching, so if I was able to come and teach at a university I wouldn't have too many problems with adjusting.

Adding another voice to the wiki was useful in helping the wiki content develop and retain self-sustainability. It enabled the $\mathrm{PhD}$ student to experience a different way of teaching in a distinctive environment and boosted her confidence and knowledge regarding using different technologies within her own teaching practice in a FE setting and may possibly help her gain a paid academic position in HE.

LR: $\quad$ Have you used any social media in your teaching?

PG: We have Moodle which is our Virtual Learning Environment and there is a discussion forum on that and I've tried to encourage them to upload their own resources particularly when they are in their dissertation year and so I've encouraged them to do that. It's been a really useful experience for me just to see how it's organised and the types of students that you get. I don't have a lot of experience in teaching eighteen year olds and I think that has been really valuable for me, because it is very different and it can be really hard to get them to engage, so it's been useful for me to watch how you do those sorts of things so, moving forward, I've got a bit more experience of working with students like that. 
This reveals the multidimensional nature of teaching and the opportunity educators have to embrace the undergraduate and postgraduate experiences in a peer-group forum enabling everyone to participate in some optimizing way.

\section{A Wiki Way of Writing for the Undergraduate Student}

Most of the students found the wiki site of some use. It took a few months to get the wiki fully functioning. There was a familiarization process whereby students became acquainted with university procedures and policies, in addition to familiarizing themselves with the wiki. Most used it as a safe forum in which to explore ideas and as a resource rich with student, lecturer, and PhD student-led content. Undergraduate students (US) used it in different ways and during different times, illustrating the benefit of this flexible, interactive pedagogical approach.

LR: $\quad$ Did you understand the wiki?
US: $\quad$ Yes.
US: $\quad$ What did you understand was its purpose?
LR: $\quad$ To share ideas on it and to look back on what we've done.
US: $\quad$ Yeah, because it's gained us an understanding of other people's
LR: $\quad$ Have you found it useful?
US: $\quad$ Yeah.

Some used the wiki as data storage and retrieval site, a place where they could refer back to previous seminar discussion content and useful references. Yet, most didn't see it as a direct means of improving their academic writing, as can be seen from one undergraduate comment below on the fact that she barely used it outside of the seminar.

US: $\quad$ Like you are only using it in the seminar, but other than that you don't have anything else to add. So, we just share our ideas in the seminar and other than that I don't think we use it.

However, many students did discuss taking care over what they wrote while simultaneously freely expressing personal opinions.

US: $\quad$ I looked at it at the start just to get an overview of what we did in class especially before the test. 
US: $\quad$ I always forget to go on it but I've been on it twice. I don't look for references or anything like that.

LR: $\quad$ So what do you go on it for?

US: $\quad$ To see what I'd written the week before because I remember spelling something wrong.

LR: $\quad$ So did you go back and change it?

US: $\quad$ Yeah.

US: $\quad$ I've been on it a few times just to look.

LR: $\quad$ At what you'd written or what other people had written?

US: $\quad$ Both.

With a little encouragement students began to voice their own opinion and write. Knowing they were writing for the seminar audience made them conscious of their writing, knowledge, and understanding, encouraging some to reflect on what and how they wrote. Some undergraduates described the benefits of having this resource and while the use of the wiki was not directly related to any form of assessment, some students used it to remember seminar content and access useful references for their timed test essay. Approximately a third of students referred to references available on the wiki in their assignment; they referenced these sources directly, rather than referencing the wiki site as directed in the wiki do's and don'ts list at the start of the module.

LR: Did anybody use it at all for the assessment?

US: $\quad$ Yeah, I looked over it.

There is evidence that the undergraduates did use the wiki in addition to their lecture-based notes and independent reading material to aid their writing in the timed test essay question. Some students cited the wiki references and arguments in their assignment. However, not all used it this way and some engaged with the wiki more than others.

\section{Levels of Participation}

Participation is depicted as central to situated learning, since it is through participation that identity and practices develop (Handley et al., 2006). Within the theory of situated learning, participation is not just viewed as a physical event or action, but rather, it involves both taking part (action) and connection (Wenger, 1998). The connection element is harder to accomplish and arguably harder to document, however there was evidence of a community of practice amongst the undergraduates whereby they discussed the significance of peer-group learning outside of their physical seating arrangements within class. 
US: $\quad$ It feels like you are actually one big group instead of just a table.

Undergraduates also acknowledged the potential for conflict of ideas and recognised that each student brought a different history and context to the wiki that was negotiated and to some extent mediated by the wiki seminar group.

US: $\quad$ I think it's good because it gives us a different perspective, I might think of something and somebody else might say it differently, but in a classroom that might not happen because some people might not feel comfortable in expressing their opinions. Especially if you write something that is not popular so if I had something to say which was different from what everybody else was saying I would just agree with what they were saying.

LR: $\quad$ But do you put anything controversial up there?

US: $\quad$ When we did the definitions I'm sure that everyone had different definitions. So, if a different group did the same definition everyone would have different things to write.

Situated learning theory emphasizes that learning is not just about developing one's knowledge and practice; rather, it involves a process of understanding who we are and in which community of practice we belong (Handley et al., 2006). Some felt more part of the community than others and there was evidence to suggest that subgroups within the overarching seminar session helped some to gain confidence in voicing their opinion and writing. Building up these safe writing environments takes time, careful management, and an understanding that peer-group learning takes on a life of its own in terms of who and how people share and write ideas. There are different forms of participation ranging from "marginal" to "full" and not everyone achieves full participation at all times (Wenger, 1988). The dynamics of power and familiarity operating within the community of practice may affect levels of participation and it is up to the educator to mediate these to enable all learners to benefit from the community of practice.

\section{Conclusions}

Essay writing is a standard practice many undergraduates are expected to demonstrate as it is thought to promote higher-order thinking (Smith, Campbell, \& Brooker, 1999) and is associated with deep learning (Xiao \& Luckling, 2008). Peer feedback has been viewed as an effective strategy used to improve student writing skills and learning achievement (Slutsky \& Wilson, 2004) and, as such, was implemented within this seminar via the use of the wiki to facilitate collaborative learning and improve undergraduates' academic writing capabilities. The use of the wiki enabled some undergraduates to voice their own opinion, capitalize on their own individual experiences, and write. 
In addition to providing graduates with the requisite knowledge to teach in their respective fields, the doctor of philosophy $(\mathrm{PhD})$ degree is aimed to prepare students to conduct original scholarly research for the dissertation and beyond (Fleming-May \& Yuro, 2009). By integrating a PhD student into the community of practice, she gained valuable experience contributing to the doctrine of an undergraduate course and assisted with the online discussions. It acted as a forum for the postgraduate to familiarize herself with $\mathrm{HE}$ teaching and enhance her and my repertoire of pedagogical teaching and learning styles.

Collaborative learning is an excellent way to optimize undergraduate, postgraduate, and lecturer skills and knowledge; it also provides a fertile safe ground to practice writing, whereby meanings are shared, renegotiated, and revisited. The wiki is one way of providing this flexible peer-group orientated space, but careful, constant management and direction is also required to oversee levels of participation within and beyond the community of practice and encourage student participation. Future work may want to review the longer-term effects of using such techniques to decipher their potential impact across other learning spheres over a prolonged period.

\section{References}

Cole, M. (2009). Using wiki technology to support student engagement: Lessons from the trenches. Computers and Education, 52(1), 141-146. Retrieved from https://doi.org/10.1016/j.compedu.2008.07.003

Common Craft. (2007, May). Wikis in plain English [Video file]. Retrieved from https://www.youtube.com/watch?v=-dnL00TdmLY

Downs, C., \& Morrison, H. (2011). Beyond the PhD: Putting the right tools in your research toolbox. Biological Research for Nursing, 13(1), 5-14. Retrieved from http://brn.sagepub.com $10.1177 / 1099800409356796$

Fleming-May, R., \& Yuro, L. (2009). From student to scholar: The academic library and social sciences PhD students' transformation. Libraries and the Academy, 9(2), 199-221. Retrieved from https://doi.org/10.1353/pla.0.0040

Handley, K., Sturdy, A., Fincham, R., \& Clark, T. (2006). Within and beyond communities of practice: Making sense of learning through participation, identity and practice. Journal of Management Studies, 43(3), 641-653. Retrieved from http://dx.doi.org/10.2753/MIS0742-1222250401

Johnson, R. T., \& Johnson, D.W. (1986). Action research: Cooperative learning in the science classroom. Science and Children, 24, 31-32. Retrieved from https://www.scribd.com/document/269314835/Johnson-R-T-Johnson-D-W-1986-Cooperative-learningin-the-science-classroom-Science-and-children-24-31-32-pdf

Jonassen, D. H., Peck, K. L., \& Wilson, B. G. (1999). Learning with technology: A constructivist perspective. Columbus, $\mathrm{OH}$, United States: Prentice Hall.

Lave, J., \& Wenger, E. (1991). Situated learning: Legitimate peripheral participation. Cambridge, England: Cambridge University Press. 
Mindel, J. L., \& Verma, S. (2006). Wikis for teaching and learning. Communications of AIS 2006, $18,2-38$.

Page, K., \& Reynolds, N. (2015). Learning from a wiki way of learning. Studies in Higher Education, 40(6), 988-1013. Retrieved from http://dx.doi.org.libaccess.hud.ac.uk/10.1080/03075079.2013.865158

Ravid, G., Kalman, Y.M., \& Rafaeli, S. (2008). Wikibooks in higher education: Empowerment through online distributed collaboration. Computers in Human Behaviour, 24, 1913-1928. Retrieved from https://doi.org/10.1016/j.chb.2008.02.010

Ruth, A., \& Houghton, L. (2009). The wiki way of learning. Australasian Journal of Educational Technology, 25(2), 135-152. doi:10.1108/18363261311314953

Slutsky, S., \& Wilson, B. A. (2004). Comparison of the three methods for teaching and evaluating writing A quasi-experimental study. The Delta Psi Epsilon Journal, 46(1), 50-61. Retrieved from https://repod.pon.edu.pl/dataset/0ba3c5de-6447-4875-ac25

Smith, D., Campbell, J., \& Brooker, R. (1999). The impact of students' approaches to essay writing on the quality of their essays. Assessment and Evaluation in Higher Education, 24(3), 327-338. Retrieved from http://dx.doi.org.libaccess.hud.ac.uk/10.1080/0260293990240306

Vygotsky, L. S. (1978). Mind in society: The development of higher mental processes. Cambridge, England: Harvard University Press.

Warhurst, R.P. (2006). "We really felt part of something": Participatory learning among peers within a university teaching-development community of practice. International Journal for Academic Development, 11(2), 111-122. Retrieved from http://dx.doi.org/10.1080/13601440600924462

Wenger, E. (1998). Communities of practice: Learning, meaning and identity. Cambridge, England: Cambridge University Press.

Xiao, Y., \& Lucking, R. (2008). The impact of two types of peer assessment on students' performance and satisfaction within a wiki environment. Internet and Higher Education, 11, 186-193. Retrieved from https://doi.org/10.1016/j.iheduc.2008.06.005

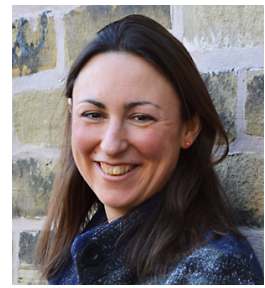

Lisa Russell is a Senior Lecturer in Education and Community Studies at the University of Huddersfield, where she has worked since 2008. Her teaching and research interests focus mainly on issues of social justice, education policy, and pedagogical practices. She is an active member of HudCRES, which takes a collaborative approach to research in policy, professional identities, and pedagogies across all education sectors and related professions. 